\title{
Variations in point prevalence of diabetes, basal metabolic rate, body mass index, blood pressure and peripheral oxygen saturation in non-smoking household cigar workers in comparison to non-smoking general population: a cross sectional comparative study
}

\section{Naveena Thotakura*}

MBBS Student, Apollo Institute of Medical Sciences, Hyderabad, Telangana, India

Received: 06 June 2016

Accepted: 01 July 2016

\section{*Correspondence:}

Naveena Thotakura,

E-mail: naveena.t.234@gmail.com

Copyright: (c) the author(s), publisher and licensee Medip Academy. This is an open-access article distributed under the terms of the Creative Commons Attribution Non-Commercial License, which permits unrestricted non-commercial use, distribution, and reproduction in any medium, provided the original work is properly cited.

\begin{abstract}
Background: The aim was to investigate the prevalence of diabetes in non-smoking cigar workers and non smoking general population. Additional Objective was to assess the variations in Basal Metabolic Rate (BMR), Body Mass Index (BMI), Blood Pressure, Peripheral Oxygen Saturation ( $\mathrm{SpO} 2)$ in non-smoking cigar workers and non smoking General Population.

Methods: Anthrapometric variables (height, weight, BMI), BMR, Random Blood Glucose (by portable glucometer), Blood Pressure (digital sphygmomanometer), Peripheral Oxygen Saturation (portable fingertip oximeter) were determined.

Results: $17 \%$ of non-smoking cigar workers and $7 \%$ of non-smoking general population were diabetic respectively. $(\mathrm{p}<0.05, \chi 2=4.735)$. Overall increase in means of Random Blood Glucose Level, Systolic Blood Pressure, Diastolic Blood Pressure, Mean Arterial Pressure, Rate Pressure Product and decrease in means of Peripheral Oxygen Saturation was recorded in nonsmoking cigar workers compared to non smoking general population which was statistically significant with $\mathrm{p}<0.05$. Prevalence rates of Prehypertension, Stage - I Hypertension, Stage - II Hypertension was found to be $27 \%, 44 \%$ and $13 \%$ in non smoking cigar workers and $37 \%, 21 \%, 9 \%$ in non-smoking general population. $(\mathrm{p}<0.001, \chi 2=24.228)$. Prevalence of Prehypertension and Hypertension was statistically significant with the period of service of cigar workers $(\mathrm{p}=0.05, \chi 2=26.279)$.

Conclusions: Increased prevalence of diabetes, prehypertension and hypertension were found in non-smoking cigar workers. Random Blood Glucose Levels, Systolic Blood Pressure, Diastolic Blood Pressure, Mean Arterial Pressure, Rate Pressure Product were increased and Peripheral Oxygen Saturation was decreased in cigar workers when compared to non smoking general population.
\end{abstract}

Keywords: BMR, BMI, $\mathrm{SpO}_{2}$, MAP, SBP, DBP

\section{INTRODUCTION}

All cigars in India are handmade and they reflect the essence of pure tobacco. ${ }^{1}$ The skillful workers roll the fermented tobacco leaves which contain large amount of nicotine than cigarettes depending on the type of leaf used in manufacturing., ${ }^{2,3}$ Prolonged exposure to particulate tobacco and nicotine for more than 10 hours a day by inhaling or swallowing and absorption through skin and mucous membrane in unhygienic conditions leads to many health problems. ${ }^{4,5}$ Nicotine levels in blood and saliva and cotinine levels in bodily fluids are found to 
be elevated even among the tobacco workers. ${ }^{6}$ Nicotine reduces body weight, body fat distribution and thus reduces body mass index and basal metabolic rate. Nicotine induces peripheral vasoconstriction by its adrenergic effects and this may contribute to observed decrease in peripheral tissue oxygen. ${ }^{8}$ Nicotine increases blood pressure and pulse rate. ${ }^{20}$ They sit with crossed legs for a long time while rolling cigar and thus their sedentary lifestyle might become a risk factor for the most challenging disease and global burden, diabetes and obesity. ${ }^{9}$ Their low socioeconomic status results in low nutritional food intake and thus low body weight and low body mass index. ${ }^{10}$ Individuals with low socioeconomic status are found to have higher blood pressure and thus higher prevalence of hypertension due to psychological and environmental stressors. ${ }^{21-23}$ Mean arterial pressure and pulse pressure which are the predictors of cardiovascular disease and rate pressure product which is an index for myocardial oxygen consumption might be increased in cigar workers due to increase in blood pressure. $^{20-23,25,26}$ But all the above outcomes are not assessed in cigar workers.

Prevalence of diabetes varies with occupation and there is very little information available in the literature now on occupational prevalence of diabetes. ${ }^{11}$ This study adds some information on occupational prevalence of diabetes in non-smoking cigar workers. This paper presents the variations in $\mathrm{BMI}, \mathrm{BMR}$ and $\mathrm{SpO} 2$ in non-smoking cigar workers and general population.

\section{METHODS}

A cross sectional study was conducted in non-smoking cigar workers and non-smoking general population in villages in and around Peddapuram Mandal, East Godavari District, Andhra Pradesh, India from $19^{\text {th }}$ Oct, 2015 to $27^{\text {th }}$ Oct, 2015. The current Prevalence of Diabetes in India is $7.1 \% .^{12-15}$ The sample size was calculated from the formula:

Sample size $=\left[Z^{2}(1-\alpha / 2) p(1-p)\right] / d^{2}$

Where $n=$ Sample Size, $Z^{2}(1-\alpha / 2)=1.96, \alpha=$ level of significance $(95 \%), \mathrm{p}=$ prevalence $(7.1 \%), \mathrm{d}=$ Absolute precision $(5 \%)$. So Sample size was found to be 102 and it had been rounded to 100 .

100 non-smoking cigar workers (24 males and 76 females) and 100 non-smoking individuals (25 males and 75 females) from general population in the age group between 20 to 60 years were selected through cluster sampling. A random selection of streets in villages and in Peddapuram town where household cigar workers were present had been done and a door to door survey had been carried out in those selected streets. All the nonsmoking cigar workers who were working with tobacco for the last 5 years were selected from the streets of Peddapuram town, Chadarada and Katravulapalli villages in Peddapuram Mandal. Nonsmoking individuals from general population were selected from the streets of Peddapuram town, Chadarada, Katravulapalli and Kadrakota villages in Peddapuram Mandal. All the smokers, alcoholics and those who take nicotine in one or the other way were excluded in the study. All of them were given a simple questionnaire which contains preliminary data and data about their work.

Weight was measured using an electronic weight scale. Subjects were weighed with minimum clothing (no correction is made for clothing) and Weight was recorded to the nearest $0.1 \mathrm{~kg}$. Height was measured using a movable slate and a tape and Height was recorded to the nearest $0.1 \mathrm{~m}$. Subjects were standing on barefoot on a flat horizontal surface, with their heels, buttocks, shoulders and back of the head touching the wall. Body Mass Index (BMI) was calculated as weight/ height ${ }^{2}\left(\mathrm{~kg} / \mathrm{m}^{2}\right)$. Subjects with BMI below 18.5 were classified to be underweight, 18.5 to 24.9 to be normal weight, 25 to 29.9 to be overweight and $>30$ to be obese. Basal Metabolic Rate (BMR) was calculated by Harris - Benedict Equation:

BMR for men in metric scale $=66.5+(13.75 \mathrm{x}$ weight in $\mathrm{kg})+(5.003 \mathrm{x}$ height in $\mathrm{cm})-(6.755 \mathrm{x}$ age in years $)$

$\mathrm{BMR}$ for women in metric scale $=655+(9.563 \mathrm{x}$ weight in $\mathrm{kg})+(1.850 \mathrm{x}$ height in $\mathrm{cm})-(4.676 \mathrm{x}$ age in years $)$

The Random Blood Glucose Levels were estimated by finger prick test using a portable glucometer (Accu-Chek Active, Model: GC, Mannheim Germany, Ser, and No: GC17028160). Capillary blood was obtained from the left ring finger first and in case if blood flow is not spontaneous/ not sufficient, then blood was obtained from right ring finger next using an automatic skin puncturing device (Accu- Chek Softclix, Model - GC, Mannheim Germany). The first drop of blood was discarded and a blood sample was taken after a spontaneous flow of blood occurred. A small drop of blood was applied on the test strip. When blood is applied to the test area, the glucose dehydrogenase enzyme (Mut.Q - GDH 2) reacts with the blood glucose and the subsequent chemical reaction changes the colour of the test area. The meter registers the colour change and converts the signal obtained into a blood glucose result. Subjects were classified as diabetic by American Diabetes Association Criteria (ADA Criteria) i.e if Random Blood Glucose level is above $200 \mathrm{mg} / \mathrm{dl}$, subject is classified as diabetic or if the participant uses some medication for diabetes.

Peripheral Oxygen Saturation was estimated using a portable non-invasive Finger Tip Pulse Oximeter (Oxywatch Fingertip Pulse Oximeter, Model: MD300C63, Beijing Choice Electronic Technology Co., Ltd, China). Subject was allowed to insert index fingertip into the silicone hole of the oximeter before releasing the clap and had to keep his/ her finger still during measurement. The pulse oximeter works by making use of Lamberts Beer Law according to Spectrum Absorption Characteristics of Reductive and Oxy hemoglobin. Two 
beams of different wavelength of light $(660 \mathrm{~nm}$ glow and $940 \mathrm{~nm}$ near infrared light) were focused onto the subject's nail through clamping finger type sensor in pulse oximeter. A measured signal obtained by a photosensitive element was shown on the oximeter's display through process in electronic circuits and microprocessor.

Blood Pressure was recorded by digital sphygmomanometer (Omron Automatic Blood Pressure Monitor, Model: HEM- 7203, Omron Healthcare Co., Ltd, Kyoto, Japan). The cuff was tied around the right arm of the subject just above the brachial artery and start button was pressed. The machine records the systolic and diastolic blood pressure along with pulse rate. The Blood Pressure were recorded thrice with a gap of 10 minutes and they were averaged. Mean Arterial Pressure, Pulse Pressure and Rate Pressure Product were calculated from the formulae: MAP $=[(2 \times$ Diastolic Blood Pressure $)+$ Systolic Blood Pressure] / 3, Pulse Pressure = Systole Diastole, Rate Pressure Product $=$ Heart Rate $\mathrm{x}$ Systolic Blood Pressure.

Hypertension was defined as an average systolic blood pressure (SBP) $\geq 140 \mathrm{mmHg}$ or an average diastolic blood pressure (DBP) $\geq 90 \mathrm{mmHg}$, or if the participant reported the current use of blood pressure lowering medication. Stage 1 hypertension is defined as systolic pressure ranging from 140 to $159 \mathrm{~mm} \mathrm{Hg}$ or a diastolic pressure ranging from 90 to $99 \mathrm{~mm} \mathrm{Hg}$. Stage 2 hypertension is a systolic pressure of $160 \mathrm{~mm} \mathrm{Hg}$ or higher or a diastolic pressure of $100 \mathrm{~mm} \mathrm{Hg}$ or higher. Prehypertension is a systolic pressure ranging from 120 to $139 \mathrm{~mm} \mathrm{Hg}$ or a diastolic pressure ranging from 80 to $89 \mathrm{~mm} \mathrm{Hg}$. Hypotension is defined as systolic pressure $<90 \mathrm{~mm} \mathrm{Hg}$ and diastolic pressure $<60 \mathrm{~mm} \mathrm{Hg}$ or is informed by the doctor that he/ she is hypertensive.
Approval from Institutional Ethical Committee, Apollo Institute of Medical Sciences and Research was sought before commencing the study. Informed consent was obtained from the volunteered individual.

The questionnaire had been assessed and all the data was fed into a computer and assessed by IBM SPSS for Windows Version 22 and verified by SOFASTATS Version 1.4.5 (Statistics open for all). Mean and Standard Deviations were estimated for continuous variables and prevalence was estimated by percentages. Students t- test for independent samples was used to test statistical significance for the continuous variables and Chi2 test for categorical data. $\mathrm{P}<0.05$ was considered to be significant.

\section{RESULTS}

Prevalence of diabetes in non-smoking tobacco workers was estimated to be $17 \%$ and that of non-smoking general population was $7 \%$. This prevalence rates were found to be statistically significant with $\mathrm{p}=0.03(\mathrm{p}<0.05)$ and Pearson's Chi Square Statistic $\left(\chi^{2}\right)$ was 4.735 . Table 1 shows the prevalence of diabetes in both the groups and also men and women separately.

The gender differences were seen to be statistically insignificant in the prevalence of diabetes with $p=0.231$ and $\chi^{2}=1.432$ for non-smoking cigar workers and $\mathrm{p}=$ 0.821 and $\chi^{2}=0.051$ for non-smoking general population. Men had more prevalence of diabetes than female in cigar workers while there was no much difference seen in general population. 4 subjects had newly detected their diabetes among non-smoking cigar workers and 3 subjects in non-smoking general population. Awareness of complications of diabetes in non-smoking cigar workers and non-smoking general population was $12 \%$ and $11 \%$ respectively (Table 1 ).

Table 1: Prevalence of diabetes with gender.

\begin{tabular}{|lllll|}
\hline & Non-Smoking Cigar Workers & \multicolumn{2}{c|}{ Non-Smoking General Population } \\
\hline & $\begin{array}{l}\text { Number of cases } \\
\text { with diabetes }\end{array}$ & $\begin{array}{l}\text { Prevalence of } \\
\text { diabetes }\end{array}$ & $\begin{array}{l}\text { Number of cases } \\
\text { with diabetes }\end{array}$ & Prevalence of diabetes \\
\hline Total $(\mathrm{n}=100)$ & 17 & $17 \%$ & 7 & $7 \%$ \\
\hline Men $\left(\mathrm{n}_{\mathrm{t}}=24, \mathrm{n}_{\mathrm{g}}=25\right)$ & 6 & $25 \%$ & 2 & $8 \%$ \\
\hline Women $(\mathrm{nt}=76, \mathrm{ng}=75)$ & 11 & $14.47 \%$ & 5 & $6.67 \%$ \\
\hline
\end{tabular}

$70 \%$ of the cigar workers had reported that they are mostly sedentary and they spend more than $7 \mathrm{hrs}$ in rolling cigar. Positive family history was recognized in $33 \%$ of cigar workers and $24 \%$ of general population.

Positive family history was reported in $23.53 \%$ (4 cases) of the diabetic patients in cigar workers and $42.86 \%$ (3 cases) of diabetic patients in general population. No statistical significance was recorded between the diabetes cases and family history of diabetes. $\quad\left(\chi^{2}=0.03\right.$ and $\mathrm{p}=0.955$ for cigar workers and $\chi^{2}=1.467$ and $\mathrm{p}=0.226$ for general population).

$40 \%$ of Cigar Workers were rolling Cigar due to financial problems and rest $60 \%$ by hereditary. Their inconvenient sedentary working style resulted in body pains in $68 \%$, back ache in $80 \%$, joint and leg pains in $75 \%$ of cigar workers. 
Random blood glucose levels, peripheral oxygen saturation, basal metabolic rate in both cigar workers and general population, pulse rate in cigar workers, systolic blood pressure, mean arterial pressure, rate pressure product, pulse pressure in general population were found to be statistically significant with $p<0.05$ i.e their distributions are not normal (Table 2). Table 3 describe the Student $\mathrm{t}$ test for independent samples. $\mathrm{t}_{\text {critical }}=\mathrm{t}_{198}=$
1.9720. This $\mathrm{t}_{\text {critical }}$ was compared with the $\mathrm{t}$ values in the above table, the result for Random Blood Glucose, Peripheral Oxygen Saturation, Systolic Blood Pressure, Diastolic Blood Pressure, Mean Arterial Pressure, Rate Pressure Product was reported to be statistically significant $(\mathrm{p}<0.05)$ which proved that there was a significant difference between the cigar workers and general population in those variables.

Table 2: Descriptive statistics.

\begin{tabular}{|c|c|c|c|c|c|c|c|c|}
\hline & \multicolumn{4}{|c|}{ Non-Smoking Cigar Workers } & \multicolumn{4}{|c|}{ Non-Smoking General Population } \\
\hline & \multirow[t]{2}{*}{ Mean \pm SD } & \multirow{2}{*}{$\begin{array}{l}\mathrm{P}- \\
\text { value }\end{array}$} & \multicolumn{2}{|c|}{ 95\% Confidence Interval } & \multirow[t]{2}{*}{ Mean \pm SD } & \multirow{2}{*}{$\begin{array}{l}\mathrm{P}- \\
\text { value }\end{array}$} & \multicolumn{2}{|c|}{ 95\% Confidence Interval } \\
\hline & & & Lower Up & & & & Lower & Upper \\
\hline Weight & $56.4140 \pm 10.86008$ & 0.862 & 54.2591 & 58.5689 & $57.8680 \pm 12.98032$ & 0.053 & 55.2924 & 60.4436 \\
\hline Height & $156.1069 \pm 7.92718$ & $<0.05$ & 154.5340 & 157.6798 & $155.8022 \pm 8.82683$ & 0.345 & 154.0508 & 157.5536 \\
\hline $\begin{array}{l}\text { Random } \\
\text { Blood } \\
\text { Glucose }\end{array}$ & $143.0500 \pm 85.47495$ & $<0.001$ & 126.0899 & 160.0101 & $117.9100 \pm 45.96443$ & $<0.001$ & 108.7897 & 127.0303 \\
\hline $\mathrm{SpO}_{2}$ & $97.8100 \pm 1.53541$ & $<0.001$ & 97.5053 & 98.1147 & $98.1900 \pm 0.72048$ & $<0.001$ & 98.0470 & 98.3330 \\
\hline BMI & $23.2706 \pm 4.31498$ & 0.711 & 22.4144 & 24.1268 & $23.6514 \pm 4.20451$ & 0.428 & 22.8171 & 24.4857 \\
\hline BMR & $1302.3250 \pm 133.33335$ & $<0.05$ & 1275.8688 & 1328.7812 & $1327.9825 \pm 210.20583$ & $<0.05$ & 1286.2731 & 1369.6919 \\
\hline $\begin{array}{l}\text { Systolic } \\
\text { Pressure }\end{array}$ & $137.420 \pm 19.31356$ & 0.111 & 133.5878 & 141.2522 & $130.9690 \pm 18.65923$ & $<0.001$ & 127.2666 & 134.6714 \\
\hline $\begin{array}{l}\text { Diastolic } \\
\text { Pressure }\end{array}$ & $84.5400 \pm 10.87154$ & 0.622 & 82.3829 & 86.6971 & $81.5600 \pm 10.16164$ & 0.667 & 79.5437 & 83.5763 \\
\hline $\begin{array}{l}\text { Pulse } \\
\text { Rate }\end{array}$ & $87.8800 \pm 13.01846$ & $<0.001$ & 85.2969 & 90.4631 & $85.6700 \pm 12.39587$ & 0.278 & 83.2104 & 88.1296 \\
\hline $\begin{array}{l}\text { Mean } \\
\text { Arterial } \\
\text { Pressure }\end{array}$ & $102.0660 \pm 12.62091$ & 0.507 & 99.5617 & 104.5703 & $98.2200 \pm 12.14660$ & $<0.05$ & 95.8099 & 100.6301 \\
\hline $\begin{array}{l}\text { Pulse } \\
\text { Pressure }\end{array}$ & $53.0700 \pm 13.51561$ & 0.098 & 50.3882 & 55.7518 & $50.0100 \pm 13.06433$ & $<0.05$ & 47.4178 & 52.6022 \\
\hline $\begin{array}{l}\text { Rate } \\
\text { Pressure } \\
\text { Product }\end{array}$ & $12095.7200 \pm 2525.44357$ & 0.075 & 11594.6172 & 12596.8228 & $11285.7900 \pm 2672.27791$ & $<0.05$ & 10755.5521 & 11816.0279 \\
\hline
\end{tabular}

$15 \%, 53 \%, 25 \%, 7 \%$ of non-smoking cigar workers and $9 \%, 52 \%, 34 \%, 5 \%$ non-smoking individuals of general population were found to be underweight, normal weight, overweight and obese respectively.

The prevalence of prehypertension, Stage - I and Stage II Hypertension was estimated to be $27 \%, 44 \%$ and $13 \%$ in cigar workers and $37 \%, 21 \%$ and $9 \%$ in general population. This prevalence rates were found to be statistically significant with $\mathrm{p}<0.001$ and $\chi^{2}=24.228$.

Prevalence of prehypertension, hypertension with age was statistically significant in cigar workers $(p=0.002$ and $\left.\chi^{2}=31.538\right)$ and general population $(\mathrm{p}=0.026$ and $\left.\chi^{2}=18.952\right)$. Prevalence of Prehypertension and Hypertension was estimated to be exactly significant with the past years of tobacco working in cigar workers $\left(\mathrm{p}=0.05\right.$ and $\left.\chi^{2}=26.279\right)$.
Table 3: Independent $t$ test for variables in cigar workers and general population.

\begin{tabular}{|lll|}
\hline & $\mathrm{t}$ & P value \\
\hline Weight & 0.859 & 0.391 \\
\hline Height & 0.257 & 0.798 \\
\hline BMI & -0.632 & 0.528 \\
\hline BMR & -1.031 & 0.304 \\
\hline Random blood glucose & 2.590 & $<0.001$ \\
\hline Peripheral oxygen saturation & -2.241 & $0.0026(<0.05)$ \\
\hline Systolic blood pressure & 2.402 & $0.017(<0.05)$ \\
\hline Diastolic blood pressure & 2.003 & $0.047(<0.05)$ \\
\hline Pulse rate & 1.229 & 0.220 \\
\hline Mean arterial pressure & 2.196 & $0.029(<0.05)$ \\
\hline Pulse Pressure & 1.628 & 0.105 \\
\hline Rate Pressure Product & 2.203 & $0.029(<0.05)$ \\
\hline
\end{tabular}


Table 4: Variation of prehypertension, hypertension with stages in non-smoking cigar workers and non-smoking general population in $\%$.

\begin{tabular}{|c|c|c|c|c|c|c|c|c|c|c|}
\hline & \multicolumn{5}{|c|}{ Non Smoking Cigar Workers $(\mathrm{n}=\mathbf{1 0 0})$} & \multicolumn{5}{|c|}{ Non Smoking General Population $(n=100)$} \\
\hline $\begin{array}{l}\text { Age of } \\
\text { workers }\end{array}$ & Normal & $\begin{array}{l}\text { Prehyper } \\
\text { Tension }\end{array}$ & $\begin{array}{l}\text { Hyper } \\
\text { Tension } \\
\text { Stage -I }\end{array}$ & $\begin{array}{l}\text { Hyper } \\
\text { Tension } \\
\text { Stage -II }\end{array}$ & $\begin{array}{l}\text { Нypo } \\
\text { Tension }\end{array}$ & Normal & $\begin{array}{l}\text { Prehyper } \\
\text { Tension }\end{array}$ & $\begin{array}{l}\text { Hyper } \\
\text { Tension } \\
\text { Stage -I }\end{array}$ & $\begin{array}{l}\text { Hyper } \\
\text { Tension } \\
\text { Stage - II }\end{array}$ & $\begin{array}{l}\text { Нypo } \\
\text { tension }\end{array}$ \\
\hline $\begin{array}{l}20-30 \\
(\mathrm{nt}=22 \\
\mathrm{ng}=24)\end{array}$ & 7 & 9 & 3 & 1 & 2 & 10 & 10 & 3 & 1 & 0 \\
\hline $\begin{array}{l}31-40 \\
(n t=32, \\
n g=32)\end{array}$ & 3 & 11 & 14 & 2 & 2 & 13 & 14 & 5 & 0 & 0 \\
\hline $\begin{array}{l}41-50 \\
\left(n_{t}=28\right. \\
\left.n_{g}=11\right)\end{array}$ & 3 & 3 & 17 & 5 & 0 & 2 & 6 & 2 & 1 & 0 \\
\hline $\begin{array}{l}51-60 \\
\left(n_{t}=19\right. \\
\left.n_{g}=33\right)\end{array}$ & 0 & 4 & 10 & 5 & 0 & 8 & 7 & 11 & 7 & 0 \\
\hline
\end{tabular}

\section{DISCUSSION}

The main aim of the study was to investigate the differences in the prevalence of diabetes between the cigar workers and general population. The current Prevalence of Diabetes in India is $7.1 \% .^{12-15}$ Reports from different studies have suggested increased prevalence of diabetes in individuals with sedentary lifestyle. ${ }^{9,16-18}$ Cigar workers are mostly sedentary while the general population mostly includes farmers, daily wage workers, housewifes e.t.c., in village population. The individuals selected in general population are not that sedentary compared to the Cigar Workers. So increased prevalence of diabetes in Cigar workers is statistically significant when compared to general population. Increased random blood glucose is also associated with sedentary lifestyle in them.

A pilot interview conducted among 10 cigar workers showed that usage of fasting and post prandial blood glucose levels by testing in lab might have a low response rate as they live on their daily wages and cannot spend their working period for these tests. And those workers who have doubt that they might have diabetes would approach for a lab test which might have resulted in a bias. So use of glucometer for the study overruled the bias and was accepted by everyone approached for the study. But using fasting and post prandial blood glucose levels instead of random blood glucose levels would give better results.

The increased prevalence of diabetes in males is due to their more sedentary lifestyle than females. Most of the females do their household chores themselves while males roll cigars and have no physical activity. Many females reported that they perform all the household chores in the morning and then they roll continuously from afternoon to evening. This might be a reason for more prevalence of diabetes in male. Its statistically insignificance may be because of the sample size which contains more females than males.

All the cigar workers work in tobacco dust. So presence of nicotine and cotinine levels in body fluids is already mentioned in a study. But variation in body weight, BMI, BMR is not found to be statistically significant. It may be because of their sedentary lifestyle. This might be the reason for $53 \%$ of the workers to be with normal weight which is quite similar to that of general population. Nicotine reduces body weight and sedentary lifestyle increases body weight. ${ }^{7,9,16-18}$ These both effects have resulted in BMI which is similar to that of general population.

In this study the number of participants in different age groups in cigar workers and general population was not equal. Age affects the Basal Metabolic Rate. This might be a reason for not finding significant difference in Basal Metabolic rate of cigar workers and general population though the separate p-values of BMR in cigar workers and general population are significant.

Due to low socioeconomic status of cigar workers nutritional deficiency especially iron deficiency was clinically found in cigar workers in Indonesia and thus low hemoglobin levels were recorded in them. ${ }^{19}$ Nicotine also has an effect on peripheral oxygen saturation. ${ }^{8}$ All these have resulted in significant decrease in peripheral oxygen saturation in cigar workers when compared to general population.

Hypertension was not included in calculating sampling size as it was not planned to include prior in the study. But it is mentioned in the study as the results are statistically significant. 
Hypertension is one of the most dangerous disorders seen in most of the cigar workers. But this hypertension seen in Cigar Workers is not age related hypertension. $73.68 \%$ of the hypertensive cigar workers are below 50 years of age while only $40 \%$ of hypertensive cases were recorded among individuals below age group of 50 years from general population. This clearly states that besides age working with pure dried tobacco and low socioeconomic status are clear risk factors in cigar workers for hypertension.

Increase in means of Mean Arterial Pressure and Rate Pressure Product in cigar workers is found to be statically significant due to increase in systolic and diastolic blood pressure. A regional estimate for the prevalence of hypertension was $21.1 \%$ for rural south India. ${ }^{24}$ As participants in 50 - 60 age group are more in general population, the prevalence of hypertension in general population is $30 \%$ in the study due to age related hypertension.

There is very little information existing in the literature on the prevalence of diabetes in cigar workers and whether body mass index, basal metabolic rate, blood pressure peripheral oxygen saturation varies in cigar workers compared to general population. So this paper would add some information to the existing literature.

\section{CONCLUSION}

Increased prevalence of diabetes, prehypertension and hypertension were found in non-smoking cigar workers. Random blood glucose levels, systolic blood pressure, diastolic blood pressure, mean arterial pressure, rate pressure product were increased and peripheral oxygen saturation was decreased in cigar workers when compared to non-smoking general population.

\section{ACKNOWLEDGEMENTS}

I would like to thank our dean sir, Dr. Dilip Mathai, Dean of Apollo Institute of Medical Sciences, Hyderabad, India. He has given me an opportunity to work on this research work though being a student and encouraged me. I would like to give my gratefulness to Yales University for free online course on biostatistics which helped me to assess the components of my study. My grateful thanks to my uncle Yedida Venkata Ramana, my father Thotakura Subba Rao, My brother E. Siva and my sisters, Saileja and Y. Padma Sri for accompanying me during door to door survey and helping me.

Funding: No funding sources Conflict of interest: None declared

Ethical approval: The study was approved by the Institutional Ethics Committee

\section{REFERENCES}

1. Cigar, 2015. Available at: https://en.wikipedia.org/ wiki/Cigar\#cite_note-theCigar-11.

2. How are Cigars different from Cigarettes 2014. Available at: http://www.cancer.org/ cancer/ cancercauses/ tobaccocancer/cigarsmoking/ cigarsmoking-cigars-vs-cigarettes.

3. Diaz DD. Critical Differences: Premium Cigars vs Cigarettes, 2007. Available at:http:// www.stogiefresh.info/edu-health/articles/criticaldifference.html.

4. International Labour Organisation. Beedi Women Workers in India: New Delhi; 2002.

5. Mittal S, Mittal A, Rengappa R. Ocular manifestations in bidi industry workers: possible consequences of occupational exposure to tobacco dust. Indian Journal of Opthamology. 2008;16(20): 72-4.

6. Quandt SA, Thomas AA, John SP, John TB. Deborah N. Environmental and behavioral predictors of salivary cotinine in latino tobacco workers. J Occup Env Med. 2001;43(10):839-926.

7. Chilero A, Faeh D, Paccaud F, Cornuz J. Consequences of smoking for body weight, body fat distribution and insulin resistance. Am J Clin Nutr. 2008;87:801-9.

8. Jensen JA, Goodson WH, Hopt HW, Hunt TK. Cigarette smoking decreases tissue oxygen. Arch Surg. 1991;126(9):1131-4.

9. Lakka TA, Laaksonen DE, Lakka HM, Männikkö N, Niskanen LK, Rauramaa R, Salonen JT. Sedentary lifestyle, poor cardiorespiratory fitness, and the metabolic syndrome. Medicine and Science in Sports and Exercise. 2003;35(8):1279-86.

10. Jeffery S, Albert JS. Socioeconomic status and obesity: a review of the literature. Psychological Bulletin. 1989;105(2):260-75.

11. Angel M, Bonacho EC, González A, Fernández C. Occupation related differences in the prevalence of metabolic syndrome. Diabetes Care. 2008;31(9):1884-5.

12. Our Bureau, Mumbai. Clinical research needed for more effective diabetes treatment: ISCR. Saturday, 2014. Available at: http://www.pharmabiz.com/NewsDetails.aspx?aid= $85115 \&$ sid $=1$.

13. Abishek R, Jayashree TM, Felix AJW, Ethirajan N, Senthil Murugan TK. Study on frequency and duration of peripheral neuropathy among known case of type ii diabetes mellitus $\geq 30$ years in chidambaram urban population. Asian Journal of pharmaceutical research. 2014;4(3):141-5.

14. Epidemiology of diabetes mellitus, 2015. Available at:https://en.wikipedia.org/wiki/Epidemiology_of_di abetes_mellitus.

15. Kaveeshwar SA, Cornwall J. The current state of diabetes mellitus in India. Australas Med J. 2014;7(1):45-8. 
16. Healy GN, Wijndaele K, Dunstan DW, Shaw JE, Salmon J, Zimmet PZ, Owen N. Objectively measured sedentary time, physical activity, and metabolic risk. The Australian Diabetes, Obesity and Lifestyle Study (AusDiab). Diabetes Care. 2008;31(2):369-71.

17. Frank B. Hu. Sedentary lifestyle and risk of obesity and type 2 diabetes. Lipids: 2003;38(2):103-8.

18. Manson AE, Skerrett PJ, Greenland P, VanItallie TB. The escalating pandemics of obesity and sedentary lifestyle a call to action for clinicians. Arch Intern Med. 2004;164(3):249-58.

19. Untoro J, Gross R, Schultink W, Sediaoetama D. The association between BMI and haemoglobin and Work Productivity among Indonesian female factory workers. European Journal of clinical Nutrition. 1998;52:131-5.

20. Omvik P. How smoking affects blood pressure. blood pressure. 1996;5(2):71-7.

21. James SA, Strogatz DS, Wing SB, Ramsey DL. Socioeconomic status, john henryism, and hypertension in blacks and whites. Am J Epidemiol. 1987;126(4):664-73.

22. James SA, Keenan NL, Strogatz DS, Browning SR, Garrett JM. Socioeconomic status, john henryism, and blood pressure in black adult. The Pitt County Study. Am J Epidemiol. 1992;135(1):59-67.
23. Colhoun HM, Hemingway H, Poulter NR. Socioeconomic status and blood pressure: an overview analysis. Journal of Human Hypertension.1998; 12(2):91-110.

24. Anchala R, Kannuri NK, Pant H, Khan H, Franco $\mathrm{OH}$, Angelantonio ED, Prabhakarand D. Hypertension in India: a systematic review and meta-analysis of prevalence, awareness, and control of hypertension. J Hypertens. 2014;32(6):1170-7.

25. Sesso HD, Stampfer MJ, Rosner B, Hennekens CH, Gaziano JM, Manson JE, et al. Systolic and diastolic blood pressure, pulse pressure, and mean arterial pressure as predictors of cardiovascular disease risk in men. Hypertension. 2000;36:801-7.

26. Gobel FL, Norstrom LA, Nelson RR, Jorgensen CR, Wang Y. The rate-pressure product as an index of myocardial oxygen consumption during exercise in patients with angina pectoris. Circulation. 1978;57:549-56.

Cite this article as: Thotakura N. Variations in point prevalence of diabetes, basal metabolic rate, body mass index, blood pressure and peripheral oxygen saturation in non-smoking household cigar workers in comparison to non-smoking general population: a cross sectional comparative study. Int J Community Med Public Health 2016;3:2112-8. 